\title{
ФОРМИРОВАНИЕ ПРОФЕССИОНАЛЬНОЙ ИДЕНТИЧНОСТИ СТУДЕНТОВ-МЕДИКОВ ПОСРЕДСТВОМ ТРЕНИНГА
}

\section{FORMATION OF PROFESSIONAL IDENTITY OF MEDICAL STUDENTS THROUGH TRAINING}

\author{
V. Mayer \\ Yu. Zhivaeva \\ E. Stoyanova
}

Summary: In the research work in theoretical and empirical aspects, we considered the possibility of forming the professional identity of medical students at the stage of study at a university through the implementation of training. In the course of a theoretical analysis of the literature, we investigated the content characteristics of the components of professional identity in various spheres of life and development of the personality of a medical student. We also analyzed the age characteristics of different stages of university training and considered the possibility of psychological support for students at these stages of training.

Keywords: professional identity, medical student, university studies, training.
Майер Валерия Сергеевна

Красноярский государственный медицинский университет им. В.Ф. Войно-Ясенецкого, г. Красноярск majer.valera@inbox.ru

Живаева Юлия Валерьяновна

к.nсх.н., доцент, Красноярский государственный медицинский университет им. В.Ф. Войно-Ясенецкого,

2. Красноярск

yul-zhivaeva@yandex.ru

Стоянова Екатерина Иннокетьевна

к.nсх.н., дочент, Красноярский государственный медицинский университет им. В.Ф. Войно-Ясенецкого,

2. Красноярск

Katya-chernova@yandex.ru

Аннотация: В исследовательской работе в теоретическом и эмпирическом аспектах мы рассмотрели возможность формирования профессиональной идентичности студентов-медиков на этапе обучения в ВУЗе посредством реализации тренинга. В ходе теоретического анализа литературы нами были исследованы содержательные характеристики компонентов профессиональной идентичности в различных сферах жизни и развития личности студента-медика. Так же мы проанализировали возрастные особенности разных этапов вузовской подготовки и рассмотрели возможность психологического сопровождения студентов на этих этапах обучения.

Ключевые слова: профессиональная идентичность, студент-медик, обучения в ВУЗе, тренинг.

вается на уровне благоприятного вхождения специалиста в профессию. Все это подводит нас к необходимости подробного изучения особенностей процесса становления личности специалиста и возможности оказания психолого-педагогического сопровождения данного формирования на всех этапах профессиональной подготовки.

В настоящее время, в связи с повышенными требованиями к уровню компетентности специалистов, наравне становится немаловажным вопрос о профессиональной идентичности. Профессиональное становление на этапе вузовской подготовки воспринимается как единый процесс постоянного развития личности профессионала и включает в себя приобретение теоретических знаний, практических умений и навыков, а также развитие индивидуальности будущего специалиста в конкретной области его деятельности. Образование компетентных специалистов - это потребность не только сегодняшнего общества, но и самого человека, реализующего процесс включения в профессиональную сферу и использующего различные варианты адаптации к динамично трансформирующейся структуре профессиональной жизни. 
Становление специалистов медиков происходит, прежде всего, в условия образовательного пространства вуза, факультета и осуществляется путем освоения ими учебно-профессиональной деятельности. Одним из основных критериев профессиональной компетентности будущих медиков является уровень развития профессионального самосознания и идентичности. Идентичность - это сложный психологический феномен, который отвечает за соответствие образа «Я» человека с его образом жизни. Впервые в психологии о таком понятии заговорил Э. Эриксон и определил идентичность, как результат активного процесса рефлексии субъекта о себе, о саморазвитии, единстве выбранных жизненных целей и действий, которые последовательно ведут к достижению этих целей. Теоретическое и методологическое значение понятия «идентичность» связано с его многомерностью как интегративного психологического феномена, который обеспечивает человеку целостность, тождественность и определенность.

Итак, целью исследования является изучение возможности формирования профессиональной идентичности у студентов-медиков посредством тренинга. Опираясь на исследования проблематики профессиональной идентичности отечественных и зарубежных ученых, в качестве гипотезы исследования мы предполагаем то, что реализация тренинга, направленного на развитие таких компонентов, как: когнитивный (представления о себе в профессии и профессиональной группе; актуализация своих личностных характеристик); эмоциональный (формирование адекватного представления о себе, как о будущем специалисте; принятие себя, как профессионала); поведенческий (актуализация механизмов самопознания, саморегуляция психических состояний в процессе деятельности и рефлексии) позволит сформировать профессиональную идентичность у студентов-медиков.

Методологическая база исследования. Теоретикометодологическую основу исследования составили концептуальные положения системной антропологической психологии: Ананьева Б.Г., Клочко В.Е., Слободчикова В.И., Шувалова А.В., а также вариант культурно-исторической концепции Выготского Л.С. В качестве концептуальных построений использовались зарубежные теории: У. Джеймса, Э. Эриксона, Ч. Кули, Дж. Мида, Д. Марсиа, и др., а также отечественные теории: АбульхановойСлавской К.А., Божович Л.И., Зеер Э.Ф., Лукьянова О.В., Мухиной В.С., Поваренков Ю.П., Рубинштейна С.Л., Шнейдер Л.Б., и др.

Для решения задач и достижения поставленной цели использованы методы: теоретические методы: теоретический анализ, обобщение и интерпретация научных данных; эмпирические методы: методика «Исследование профессиональной идентичности» (МИПИ) Л.Б.Шней- дер, методика «Якоря карьеры» Э. Шейна (перевод и адаптация В.А. Чикер, В.Э. Винокурова), методика «Тест «Кто Я?» М. Куна, Т. Макпартленд (модификация Т.В. Румянцевой); методы математической обработки экспериментальных данных: пакет прикладных компьютерных программ для обработки данных Microsoft Excel и статистический пакет STATISTICA 16.0, t-критерий Стьюдента.

Главным вопросом при проведении нашего эмпирического исследования является вопрос изучения процесса формирования профессиональной идентичности на этапе вузовского обучения.

Экспериментальной базой исследования являлся «Красноярский государственный медицинский университет им. В.Ф. Войно-Ясенецкого»г. Красноярск. Выборка исследования представлена студентами 2 курса специальности «Лечебное дело» в количестве: пилотажное исследование 120 человек, экспериментальное исследование 20 человек (10 человек экспериментальная группа и 10 человек контрольная группа).

В результате первичной диагностики нами были выявлены особенности сформированности профессиональной идентичности. Для выявления равноценности состава групп мы использовали t-критерий Стьюдента для несвязанных выборок. По методике изучения профессиональной идентичности (МИПИ) Л.Б. Шнейдер полученное значение $\mathrm{t}$ эмпирическое $(\mathrm{t}$ эмп. $=1,8)$ находится в зоне незначимости (t кр. $=2,04 ; \mathrm{p}<0,05)$, что говорит о статистической несущественности различий между выборками.

По методике «Кто Я?» М. Кун, Т. Макпартленд (модификация Т.В. Румянцевой) значение $\mathrm{t}$ эмпирическое (t эмп. $=1,6)$ так же находится в зоне незначимости (t кр. $=2,04 ; p<0,05)$, что так же свидетельствует о статистической несущественности различий между выборками. По методике «Якоря карьеры» Э. Шейна (перевод и адаптация В.А. Чикер, В.Э. Винокурова) полученное значение $\mathrm{t}$ эмпирическое ( $\mathrm{t}$ эмп. $=1,7)$ так же находится в зоне незначимости (t кр. $=2,04 ; p<0,05$ ), что доказывает статистическую несущественность различий между выборками.

Исходя из показателей первичной диагностики, для определения эффективности программы тренинга, экспериментальной группой была определены 1 экспериментальная группа и 2 группа контрольная.

В ходе исследования нами была создана программа тренинга, при составлении которой мы опирались на работы таких авторов, как: Лукьянов О.В. «Проблема становления идентичность в эпоху социальных изменений», «Проблема идентичности и психическая ригидность в психологической и образовательной практике». Поваренков Ю.П. «Проблемы психологии профессио- 
нального становления личности», «Психологическое содержание профессиональной идентичность». Абульханова-Славская К.А. «О путях построения психологии личности», «Стратегии жизни». Шнейдер Ю.Б. «Профессиональная идентичность».

Цель программы - формирование профессиональной идентичности через развитие таких компонентов, как: когнитивный, эмоциональный и поведенческий, а именно расширение представления о себе как о профессионале, развитие профессиональных потребностей, эмоционально-оценочного отношения к себе, как к будущему специалисту, актуализация механизмов самопознания.

\section{Задачи программы:}

1. Развить понятийный аппарат студентов: «идентичность», «профессиональная идентичность», «осознанность», «профессиональное становление», «личностные качества», «профессиональное поведение».

2. Развить способности студентов оценивать свои личностные особенности и качества, дифференцировать свои возможности необходимые для дальнейшей профессиональной деятельности, умение оценивать свои личностные характеристики и соотносить с требованиями выбранной профессии, давать характеристику своему поведению и внутренним переживаниям.

3. Активизировать интерес и значимость к выбранной профессиональной деятельности.

4. Создать условия «включения» в профессиональную деятельность, смоделировать свое поведение с учетом оценки своего потенциала, сложности профессиональной деятельности, особенностью сферы профессии.

После реализации комплекса тренинговых мероприятий, мы провели повторную диагностику для двух групп по всем трем методика. Рассмотрим каждую из них. По методике «Изучение профессиональной идентичности» (МИПИ) Л.Б. Шнейдер мы получили следующие результаты:

В ходе исследования с помощью методики изучения профессиональной идентичности Л.Б. Шнейдер у контрольной группы были получены следующие результаты: диффузная идентичность - 23,6\% этим исследуемым свойственно пассивная профессиональная деятельность - накопление знаний и навыков о выбранной специальности, можно отметить так же наличие интереса к профессии. Псевдоидентичность - 29,5\%, для этих респондентов характерно стабильное отрицание своей уникальности или напротив, ее достаточно высокая выраженность, а также они стараются любыми средствами достичь поставленной цели. Преждевременная идентичность - 35,4\%, для этих исследуемых характерно от- сутствие активной профессиональной деятельности. Мораторий - 11,8\%, этим респондентам характерно наличие тревожности, активной реализации профессиональной деятельности по образцу или регламенту, можно отметить личностную заинтересованность в профессии и оформление плана ближайшего развития. Достигнутая позитивная идентичность - 0\%.

В ходе исследования с помощью методики изучения профессиональной идентичности Л.Б Шнейдер у экспериментальной группы были получены следующие результаты: диффузная идентичность - 11,8\%, этим исследуемым свойственно пассивная профессиональная деятельность - накопление знаний и навыков о выбранной специальности, можно отметить так же наличие интереса к профессии. Псевдоидентичность - 17,7\%, для этих респондентов характерно стабильное отрицание своей уникальности или напротив, ее достаточно высокая выраженность, а также они стараются любыми средствами достичь поставленной цели. Преждевременная идентичность - 23,6\%, для этих исследуемых характерно отсутствие активной профессиональной деятельности. Мораторий - 41,3\%, для этих респондентов характерно наличие тревожности, активной реализации профессиональной деятельности по образцу или регламенту, можно отметить личностную заинтересованность в профессии и оформление плана ближайшего развития. Достигнутая позитивная идентичность - 5,9\%.

Таким образом, в ходе повторной диагностики по методике изучения профессиональной идентичности, мы получили следующие результаты: Для контрольной группы преобладающий статус идентичности является преждевременная идентичность - 35,4\%. Для экспериментальной группы преобладающим статусом идентичности является мораторий - 41,3\%, и у одного респондента выявлена достигнутая идентичность - 5,9\%.

Теперь обратимся к результатам повторной диагностике по методике «Кто Я?» М. Кун, Т. Макпартленд (модификация Т.В. Румянцевой), и рассмотрим полученные результаты для каждой группы.

В ходе исследования с помощью методики «Кто Я?» М. Кун, Т. Макпартленд (модификация Т.В. Румянцевой) у контрольной группы были получены следующие результаты: учебно-профессиональная идентичность - 47,2\%, примерами данной категории являются такие, как: «студент», «ученица», учусь в институте. Данные утверждения объективно относятся к определенным статусам и классам и свидетельствуют о низком уровне учебно-профессиональной ориентации. Деятельная идентичность - 53,1\%, утверждения по этой шкале были следующими: «люблю учебу», «люблю читать», «занимаюсь в бассейне», «люблю решать задачи», «профессионально рисую». Данная шкала включает в себя обозначение занятий, интересов, увлечений, а также связана со способностью 
сосредоточиться на себе. Перспективная идентичность, связанная с учебно-профессиональной сферой - 23,6\%, примерами данной категории являются: «будущий выпускник», «будущий врач», «будущий специалист». Полученный данные по этой шкале свидетельствуют о том, что у студентов контрольной группы низкий уровень ориентации на дальнейшую перспективу профессиональной деятельности. Рефлексивная идентичность: персональная идентичность - 88,5\%, высказывания по этой шкале: «умная», «разносторонняя», «эмоциональная», «искренняя», «общительный», «упрямая». Экзистенциальное «Я» - 59,0\%: «индивидуальность», «личность», «сущность». Полученные данные говорят нам о том, что у респондентов, в целом, высокий уровень рефлексивной идентичности, который выражается в осознание личностью собственного единства, ориентации на самого себя, на свою глубинную сущность, а также жизненные установки и личностные свойства.

В ходе исследования с помощью методики «Кто Я?» М. Кун, Т. Макпартленд (модификация Т.В. Румянцевой) у экспериментальной группы были получены следующие результаты: учебно-профессиональная идентичность 82,6\%, примерами данной категории являются такие, как: «студент», «обучающийся», «учусь на медика», «уже работаю санитаром». Данные утверждения объективно относятся к определенным статусам и классам и свидетельствуют о высоком уровне учебно-профессиональной ориентации. Деятельная идентичность - 47,2\%, утверждения по этой шкале были следующими: «был на тренинге», «люблю читать», «люблю саморазвиваться», «люблю играть на гитаре». Данная шкала включает в себя обозначение занятий, интересов, увлечений, а также связана со способностью сосредоточиться на себе. Перспективная идентичность, связанная с учебно-профессиональной сферой - 76,7\%, примерами данной категории являются: «будущий хирург», «будущий специалист в медицине». Полученный данные по этой шкале свидетельствуют о том, что у студентов-медиков экспериментальной группы высокий уровень ориентации на дальнейшую перспективу профессиональной деятельности. Рефлексивная идентичность: персональная идентичность - 94,4\%, высказывания по этой шкале: «ответственный», «настойчивая», «добрый», «терпеливый», «вспыльчивая», «искренний», «умный». Экзистенциальное «Я» - 59,0\%: «личность», «свободная личность», «субъект», «осмысленный человек». Полученные данные говорят нам о том, что у респондентов, в целом, высокий уровень рефлексивной идентичности, который выражается в осознание личностью собственного единства, ориентации на самого себя, на свою глубинную сущность, а также жизненные установки и личностные свойства.

Таким образом, в ходе повторной диагностики по методике «Кто Я?», были получены следующие результаты: Для контрольной группы результаты в процентном соотношении по шкалам: учебно-профессиональная идентичность, деятельная идентичность, перспективная идентичность и рефлексивная идентичность изменены незначительно по отношению к результатам первичной диагностики. Для экспериментальной группы результаты в процентном соотношении по шкалам: учебно-профессиональная идентичность и перспективная идентичность изменены с низкого уровня, который был выявлен в ходе первичной диагностики, на высокий уровень.

Обратимся к результатам повторной диагностике по методике карьерных ориентаций «Якоря карьеры» Э. Шейн (перевод и адаптация В.А. Чикер, В.Э. Винокурова) для каждой группы.

В ходе исследования с помощью методики карьерных ориентаций «Якоря карьеры?» Э. Шейна (перевод и адаптация В.А. Чикер, В.Э. Винокурова) у контрольной группы были получены следующие результаты: автономия - 35,4\%, у этих респондентов первичной заботой личности является - освобождение от правил, предписаний и ограничений, которые предоставляет организация, а также предпочитают выполнять работу в своем темпе, по собственным стандартам. Возможны трудности, которые с установленными правилами, процедурами, рабочим днем, дисциплиной, формой одежды и т.п. Стабильность работы - 23,6\%, для этих респондентов значимой потребностью является безопасность, для них важно постоянная работа с минимальной вероятностью увольнения и различными социальными гарантиями от работодателя. Такие личности сопоставляют свою учебу со своей дальнейшей карьерой. Служение - 23,6\%, для этих респондентов характерна связь между выбором места работы и желанием приносить пользу людям и обществу. Главной ценностью является возможность эффективно использовать свои умения, знания и опыт для реализации цели, которая является общественно важной. Интеграция стилей жизни - 5,9\%, у этих исследуемых карьера ассоциируется с их общем стилем жизни. Поддерживать конкретный образ жизни, который уже сложился, для них важнее, чем добиваться успеха в карьере. Для них важно, чтобы и их образ жизни, и карьера находились в уравновешенном состояние и одно на другим не преобладало. Профессиональная компетентность - 11,8\%, что отражает недостаточную направленность студентов на развитие своего потенциала, способностей в определенной профессиональной сфере.

В ходе исследования с помощью методики карьерных ориентаций «Якоря карьеры?» Э. Шейна (перевод и адаптация В.А. Чикер, В.Э. Винокурова) у контрольной группы были получены следующие результаты: автономия - 17,7\%, у этих респондентов первичной заботой личности является - освобождение от правил, предписаний и ограничений, которые предоставляет организация, а также предпочитают выполнять работу в своем 
темпе, по собственным стандартам. Возможны трудности, которые с установленными правилами, процедурами, рабочим днем, дисциплиной, формой одежды и т.п. Стабильность работы - 5,9\%, для этих респондентов значимой потребностью является безопасность, для них важно постоянная работа с минимальной вероятностью увольнения и различными социальными гарантиями от работодателя. Такие личности сопоставляют свою учебу со своей дальнейшей карьерой. Служение - 35,4\%, для этих респондентов характерна связь между выбором места работы и желанием приносить пользу людям и обществу. Главной ценностью является возможность эффективно использовать свои умения, знания и опыт для реализации цели, которая является общественно важной. Интеграция стилей жизни - 5,9\%, у этих исследуемых карьера ассоциируется с их общем стилем жизни. Поддерживать конкретный образ жизни, который уже сложился, для них важнее, чем добиваться успеха в карьере. Для них важно, чтобы и их образ жизни, и карьера находились в уравновешенном состоянии и одно над другим не преобладало. Профессиональная компетентность - 35,4\%, для этих респондентов характерно наличие способностей и талантов в определенной профессиональной сфере, а также при достижении высоких результатов в профессиональной деятельности они чувствуют себя наиболее успешными и наоборот.

Таким образом, в ходе повторной диагностики по методике «Якоря карьеры», мы получили следующие результаты:

1. Для контрольной группы результаты в процентном соотношении по шкалам: автономия, стабильность работы, служение, интеграция стилей жизни и профессиональная компетентность изменены незначительно по отношению к результатам первичной диагностики.

2. Для экспериментальной группы результаты в процентном соотношении по шкалам: служение и профессиональная компетентность увеличились, по сравнению с полученными данными в ходе первичной диагностики.

Для определения эффективности проведения тренинга, мы рассмотрели показатели зоны значимости при определении эмпирического значения t-критерия Стъюдента для связанных выборок у экспериментальной группы после формирующего эксперимента.

Анализ результатов статистической обработки данных по методике изучения профессиональной идентичности по МИПИ Л.Б. Шнейдер показал, что полученное значение $\mathrm{t}$ эмпирическое ( $\mathrm{t}$ эмп. $=3,9$ ) находится в зоне значимости (t кр. $=2,12 ; p<0,05)$, что свидетельствует о статистической существенности различий между показателями первичной и повторной диагностик.

При анализе полученных результатов по методике «Кто Я?» М. Кун, Т. Макпартленд (модификация Т.В. Румянцевой) было выявлено, что значение $t$ эмпирическое (t эмп.=3,9) же находится в зоне значимости (t кp. $=2,12 ; \mathrm{p}<$ 0,05), что так же свидетельствует о статистической существенности различий.

При анализе результатов, полученных по методике «Якоря карьеры» Э. Шейна (перевод и адаптация В.А. Чикер, В.Э. Винокурова), выявлено полученное значение $t$ эмпирическое (t эмп.=4,9) так же находится в зоне значимости (t кр.=2,14; p < 0,05), что доказывает статистическую существенность различий между первичной и повторной диагностик у экспериментальной группы.

Таким образом, определение эффективности проведения тренинга, посредством t-критерий Стьюдента, показало существенность различий между показателями первичной и повторной диагностик по всем трем методика, которые применялись в нашем исследовании.

В ходе исследования мы выяснили, что оптимизация процесса формирования профессиональной идентичности студентов-медиков возможна через применение технологии тренинга. Содержание психологического сопровождения формирования профессиональной идентичности направленно на решение возникающих трудностей в процессе развития личности студентов-медиков, их способности к самоанализу и самокритике.

Итоги реализация технологии психологического сопровождения становления профессиональной идентичности позволили зафиксировать изменения, произошедшие со студентами после формирующего эксперимента по ряду параметров профессиональной идентичности, а также увидеть положительную динамику в изменении статуса профессиональной идентичности.

\section{ЛИТЕРАТУРА}

1. Александров, Е.П. 0 смысловых барьерах профессиональной идентичности студентов / Е.П. Александров, Е.В. Лащева // Культурная жизнь Юга России. 2017. - №3. - C. 1-4.

2. Головей, Л.А. Профессиональное развитие личности: начало пути [Электронный ресурс] : эмпирич. исслед. / Л.А. Головей, М.В. Данилова, Л.В. Рыкман, М.Д. Петраш, В.Р. Манукян, М.Ю. Леонтьева, Н.А. Александрова. — СПб.: Нестор-История, 2015. — 336 c. Режим доступа: https://books.google.ru/books

3. Денисова, О.В. Становление профессиональной идентичности студента-медика в образовательном процессе вуза: автореф. дис. ... канд. психол. наук : 
19.00.07 / О.В. Денисова. - Екатеринбург, 2008. - 26 с.

4. Зеер, Э.Ф. Психология профессионального самоопределения в ранней юности: учеб. пособие / Э.Ф. Зеер, 0.А. Рудей. — М.: МПСИ, 2008. — 256 с.

5. Клочко, В.Е. Личностная идентичность и проблема устойчивости человека в меняющемся мире: системно-антропологический ракурс / В.Е. Клочко, 0.В. Лукьянов // Вестник Томского государственного университета. - 2009. - № 324. - С. 333-336.

6. Лукьянов, О.В. Самоидентичность как условие устойчивости человека в меняющемся мире: дис. ... д-ра психол. наук: 19.00.01 / 0.В. Лукьянов. - Томск, 2009. -289 C.

○ Майер Валерия Сергеевна (majer.valera@inbox.ru), Живаева Юлия Валерьяновна (yul-zhivaeva@yandex.ru),

Стоянова Екатерина Иннокетьевна (Katya-chernova@yandex.ru).

Журнал «Современная наука: актуальные проблемы теории и практики»

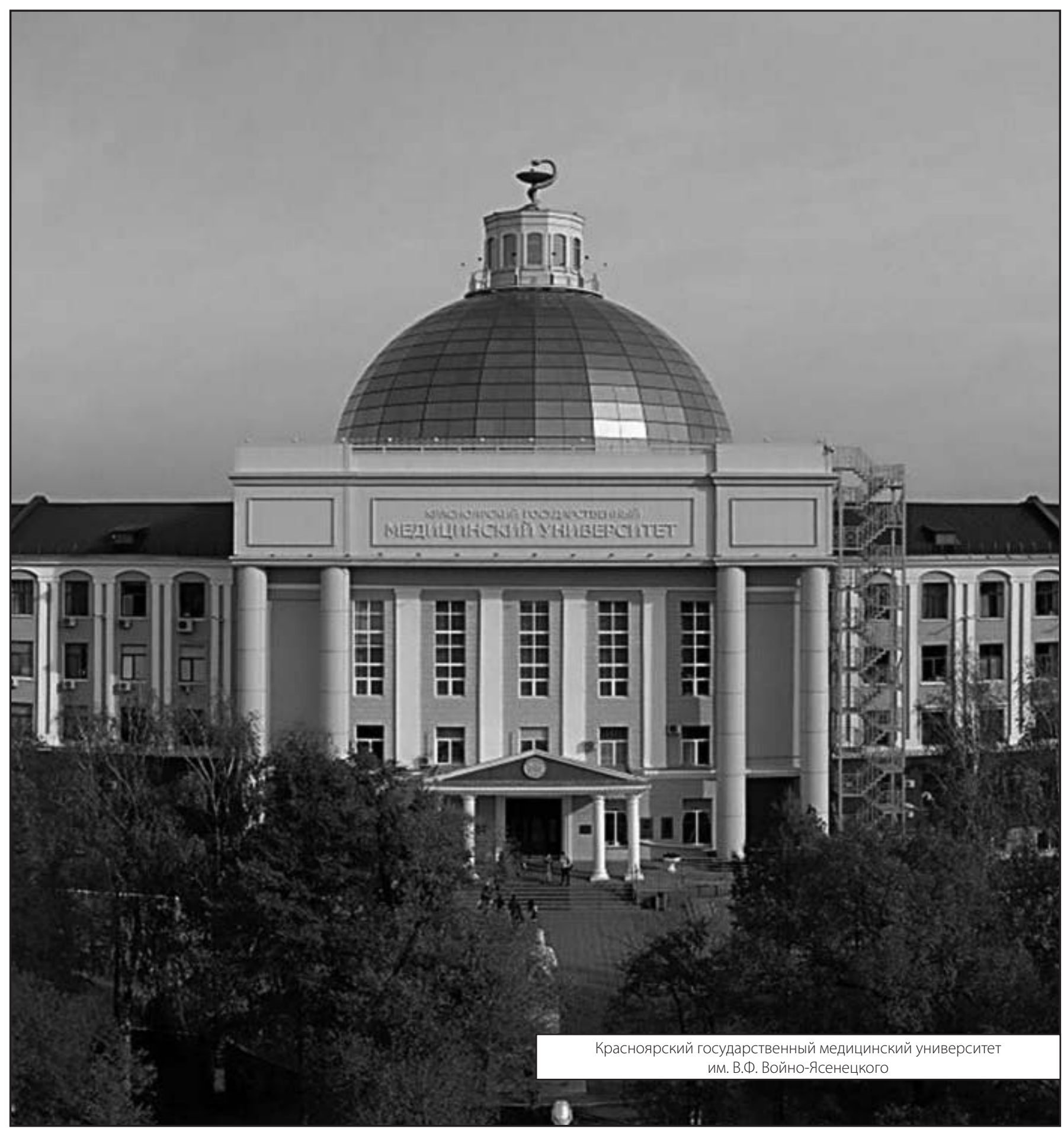

